\title{
Discussion on the Development Mode of Agricultural Industrialization and Its Innovation
}

\author{
Dan Huang \\ Wuhan Donghu University, Wuhan City, Hubei Province, 430000, China
}

\begin{abstract}
Agricultural industrialization is a part of agricultural modernization, and the organization of agricultural industrialization is an important part of promoting agricultural industrialization. The model of the organization of agricultural industrialization is to study how to unite the various stakeholders or the business entity who have joined agricultural industrialization. Based on the author's learning and practical experience, this paper first analyzed the managing organization model of modern agricultural industrialization, and then discussed the problems existing in the development model of agricultural industrialization, and finally put forward the innovative path of agricultural industrialization's development model. This paper argues that it is the future direction of agricultural industrialization to reconstruct the combination mode of agricultural management, promote the transformation of agricultural development mode and create a service oriented agriculture .

Key words: Agriculture; Industrialization; Development model; Innovation
\end{abstract}

\section{Introduction}

Agricultural industrialization has become the common trend of global agriculture, and world agriculture has entered to the era of industrialization. As a concrete manifestation of agricultural industrialization, the organization model of agricultural industrialization directly reflects whether the agricultural management system conforms to the historical trend; whether it can innovate and develop in accordance with the requirements of marketization and 
internationalization, and determines whether it will be up in the improvement of agricultural industrialization level[1]. Therefore, it is the only way to improve the agricultural industrialization management level, promote the adjustment of agricultural industrial structure, and realize the modernization of agriculture by deepening the understanding of various organizational models of agricultural industrialization and finding the suitable agricultural industrialization organization mode.

\section{Modern Agricultural Industrialization Management Mode}

\subsection{Leading enterprises driven type}

The current three kinds of industrial organization models in China are leading enterprise-driven, professional market-driven, cooperative and other intermediary organizations driven type. The main mode of operation in China is leading enterprise-driven agricultural industrialization whose basic organizational model is "Companies + Farmers." The companies here mostly refer to the local leading enterprises. Because the types of leading enterprises are mostly for agricultural and sideline products processing or circulation enterprises, through the contract contract, joint-stock cooperative system and other interests of the linkage mechanism to drive farmers engaged in professional production, and production, processing, sales of organic integration, as well as the implementation of integrated management with obvious industry leading role, if the formation of industrial clusters can also have a clustering effect. Therefore, many areas will play a leading enterprise driven as a top priority of agricultural development, the government has always insisted on both the introduction and cultivation of the industrialization of this model to promote the development of the organization[2].

\subsection{Professional market driven type}

Professional market-driven type refers to the professional market or professional trading center of agricultural products as the basis, combined with regional resources or industrial advantages, promoting regional agricultural professional production and driving farmers into specialized production. Thereby it can expand the scale of agricultural production scale advantage, and then it can have advantages in formation of industrial and promote regional economic development. Professional market generally formed by the spontaneous formation of the market or the government to guide the formation of training. Standardized market function can better protect interests of the transaction between farmers and enterprises[3]. Without changing the mode of family business organization, through the continuous development and expansion of professional markets, it can guide farmers to choose suitable for market characteristics of agricultural production to increase farmer income. This model can make farmers better organizing market-oriented production, and promote 
local agricultural regionalization, large-scale and specialized production. But it will be affected to traffic conditions, information transmission and other factors.

\subsection{Cooperatives and other intermediary organizations driven type}

Driven model of cooperatives and other intermediary organizations is based on professional cooperative economic organizations (including farmers' professional and technical associations) and cooperatives as intermediaries, and the cooperative system or joint-stock cooperative system as the link of the interests to achieve agricultural production, to realize the integration of agricultural production, production, sales and trade, industry and agriculture. And its basic organizational model is "cooperative economic organization + farmers". On the basis of the household contract responsibility system in rural areas, through the practice of farmers themselves, cooperation and sharing of spontaneous formation of cooperative economic organizations are set up on the basis of equality and mutual benefit and decisions on major issues are made by all members together. This model is the development of the market economy in the process of spontaneous formation, and its management is more democratic. All members participate in together and are free to join and exit in accordance with the Articles of Association.

\section{The Problems in the Development Model of Agricultural Industrialization}

\subsection{The interest mechanism is not perfect}

At present, China (our country is not translated into China, not our country) actively explores the agricultural industrial management of the various interests of the main mechanism of the linking mechanism and distribution mechanism, and forms a variety of characteristics and effective interest link. However, there are still some problems such as irregularity, imperfection and instability in the mechanism of interest linkage between the organizations of agricultural industrialization. Relationships between organizations and farmers also failed to establish a mechanism of risk sharing mechanism and effective sharing of interests, as well as the operation of such a security system. And it has not formed a real sense of the economic interests of the community yet[4]. Default phenomenon is very common, and the phenomenon of farmers not performing the contract is more prominent especially.

\subsection{Leading enterprises are not competitive}

Leading enterprises are the backbone and pillar of agricultural industrialization management. The development scale and strength of leading enterprises are directly related to the growth rate of agricultural production efficiency, to the 
extent of income increase and the breadth and depth of farmers to the market as well as the speed of development of agricultural industrialization. But at present, the real economic strength of the leading enterprises are not enough, and most of these enterprises are featuring with small-scale, weak economic strength and narrow radiation, resulting in weak impetus and lack of resistance to market risk and natural risk[5]. They did not form a considerable leading economic chain, so it is difficult to promote the development of related industrial chain. As leading enterprises are few as economic strength of the leading enterprises being fewer, leading enterprises can not lead a wider range of agriculture and a greater number of farmers to enter the domestic and international markets, can not drive the industrialization of agriculture to the depth of development, so that it limits the ability and scope of agriculture and farmers, and hinders the rapid development of agricultural industrialization.

\subsection{Agricultural industrialization policy to be improved}

Agricultural industrialization can be said as the second step of rural reform deepening following the household contract responsibility system and the rapid development of township enterprises. Although the government of Linyi city introduces a number of policies to guide and support them at different periods, but the policies and regulations are not complete and perfect, they can not make the industry a higher level. At the present circumstances, it urgently requires a series of policies and regulations cross-sector, cross-region and cross-department to guide and regulate the industrialization of agriculture. So it can truly unite the industrial and agricultural, urban and rural organic coordination well to be a formation of closely linked communities to promote the further deepening and development of agricultural industrialization.

\section{The Innovation Path of Agricultural Industrialization Development Model}

\subsection{Optimization of the organization of the contract system}

Develop special industries and high-quality products relying on local resources. With the mode of one industry in one rural and one product in one village, agricultural industrialization can gradually expand the scale and improve product quality, accelerate the development of leading enterprises, improve the operational efficiency of the organization, and built up the formation of regional leading industries, high-quality products and Industrial clusters[6]. In this kind of industrialized management organization, the status of the two sides of the contract is unequal, at the same time the contract itself is imperfect and the contract is not stable. Therefore, it is necessary to formulate and improve the relevant laws and regulations, improve the contract, improve the farmers' awareness of the market and the legal system, and introduce competition 
mechanism, so that "leading enterprises" and farmers (base) can have the twoway selection and finally improve the operational efficiency .

\subsection{Strengthen the horizontal integration of organizational innovation}

Cooperatives are organized by the peasants themselves. They are managed by the peasants themselves and represent the interests of the peasants. Various types of non-governmental cooperative service organizations (such as professional and technical associations and professional cooperatives) provide social services for farmers' industrialized management, and to a certain extent they can change farmer 's weak position. The cooperative (intermediary) can reduce transaction costs, market risks, technical risks and ultimately increase the incomes of farmers to protect the interests of farmers. Therefore, the government and all sectors of society should make great propaganda to encourage farmers to form cooperatives, especially professional cooperative organizations, so that the size and number of cooperatives can be greatly improved; Strengthen the cooperative organization, improve management system, and improve the service and management level. According to local conditions, intermediaries can take different forms of organization combined with the local agricultural development characteristics and resource advantages to have their own development.

\subsection{Accelerate the development of joint-stock cooperative system}

This is a kind of partnership business organization of capital and labor union, and this double combination makes it have characteristics of dual nature in the internal management system and distribution system and many other aspects. Contract system and cooperative system can not meet the requirements of largescale socialized agricultural production, and have limitation of system[7]. The essence of agricultural industrialization management organization innovation is to create a kind of socialized means of production under the demand of large-scale production of agricultural socialization to meet the needs of large-scale socialized production of agriculture on the basis of household contract responsibility system. The stock cooperative system can better promote the flow of different factors of production and restructuring, to achieve "a single capital to the transformation of social capital" and to meet the needs of agricultural industrialization and organizational innovation, so it becomes the inevitable choice of organizational innovation of industrialization of agriculture. And reform of land should be carried out to speed up the transfer of land and to create conditions for farmers to use land-use rights to increase their stake. Pay more attention to policy supporting to the shareholding cooperative system, carrying out tax relief as well as improving and establishing various investment and financing channels. Pay attention to the development of capital, land, labor, technology, information, property rights and other agricultural factors of production market. Promote the flow of agricultural resources and production factors, promote agricultural resources and production factors into capital, and improve agricultural products and agricultural factors market operation mechanism through the industrialization 
of agricultural management system innovation for the development of agricultural industrialization to provide a strong organizational system protection, and then realize the scale of agricultural production, intensive, socialization and modernization.

\section{Conclusion}

For a long period of time in the current and future, we should pay particular attention to driving the new urbanization to the leading role of agricultural industrialization for complying with changes of China's economic and social development at major stages and promoting agricultural industrialization management. This paper argues that the innovation of agricultural industrialization management is an important way to build a new socialist countryside and realize the industrialization of agriculture.

\section{Acknowledgements}

This work was supported by the grants from Hubei Provincial Collaborative Innovation Centre of Agricultural E-commerce(under construction)(Wuhan Donghu university research [2016] No.15 Document.

\section{References}

[1] Liang Junyan, Li Zhifeng. Innovation of agricultural industrialization in Gansu Province development path. Journal of Longdong University, (02), pp.105-108, 2015.

[2] Cai Hailong. Organization of agricultural industrialization organization and its innovation path. Chinese Rural Economy, (11), pp.4-11, 2013.

[3] Zhang Guanghai, Wulan Tuoya. Research on the industrialization and pattern of leisure agriculture in China, (10), pp.30-37, 2011.

[4] Wang Jinhe.Discussion on Innovation of Agricultural Industrialization Cooperative Organization. Agricultural Sciences of Anhui, (09), pp.36-37, 2010.

[5] Zhao Donglong. Imagination and countermeasures of the development model of the innovative agricultural industrialization in Linyi City. Agricultural Sciences in Guizhou, (07), pp.218-220, 2009.

[6] Huang Liangui, Zhang Zhaoxin, Zhang Tao. Current Situation, Effect and Future Development of Agricultural Industrialization in China. Economic Research, (31), pp.23-33, 2008. 
[7] Jian Xiaoying, Sun Chuanfan, Zhang Xiuping.Technical Commissioners System and the Development of Agricultural Industrialization. Science Management Research, (02), pp.41-43, 2007. 